\title{
Characteristics of joint resistance with different kinds of HTS tapes for heater trigger switch
}

\author{
Jeyull Lee, Young Gun Park ${ }^{a}$, Woo Seung Lee ${ }^{a}$, Hyun Chul Joa, Yong Soo Yoon*, , and Tae Kuk Ko \\ a Yonsei University, Sinchon-dong, Seodaemun-gu, Seoul, Korea \\ b Shin Ansan University, Choji-dong, Danwon-gu, Ansan-si, Gyeonggi-do, Korea
}

(Received 5 February 2014; revised or reviewed 26 March 2014; accepted 27 March 2014)

\begin{abstract}
Recently, many researches on the system of superconducting power supply and superconducting magnetic energy storage (SMES) using high temperature superconducting (HTS) tapes has been progressed. Those kinds of superconducting devices use the heater trigger switches that have a control delay problem at moments of heating up and cooling down. One way to reduce the time delay is using a different HTS tape at trigger part. For example, HTS tape having lower critical temperature can reduce time delay of heating up and heating down stage for heater trigger operation. This paper deals with resistances joint with different kinds of HTS tapes which have different properties to verify usefulness of the suggested method. Three kinds of commercial HTS tapes with different specifications are selected as samples and two kinds of solders are used for comparison. Joint is performed with temperature and pressure controllable joint machine and the joint characteristics are analyzed under the repeatable conditions.
\end{abstract}

Keywords: Lap Joint, Joint resistance, Thermal switch, Flux pump

\section{1. 서 론}

기존 화석연료 기반의 에너지원의 가격 상승 및 원전의 안전성 문제가 최근 이슈가 되면서 태양광 발전 및 풍력 발전과 같은 대체에너지에 대한 관심이 높아지고 있다. 그러나 모든 대체에너지원이 발전 용량을 컨트롤하는 것이 가능한 것이 아니다. 이와 같은 단점을 보완하기 위해 과하게 발전된 에너지는 저장, 부족한 에너지는 방전을 하는 형태로 발전 용량을 제어하는 방법을 사용하기 위해 에너지 저장 장치에 대한 연구가 활발히 진행되고 있다. 특히 에너지 저장 장치의 단가를 낮추고 안정성을 높이기 위해 고온 초전도(HTS) 선재를 활용한 Superconducting power supply, Superconducting Magnetic Energy Storage(SMES) 등의 시스템에 대한 연구가 진행되고 있다. 그러나 HTS 코일을 이용한 에너지 저장 장치의 경우, 전류의 충전 및 방전을 위해 Heater trigger switch를 사용하게 된다[1]. Heater trigger switch는 초전도 선재의 일부분에 임계온도 이상의 열을 가하여 발생하는 저항을 이용한 스위치로, 온도의 상승 및 감소에 의존하게 된다. 따라서 스위치로서 작동하는데 있어서 시간 지연이 발생하며 이를 향상시키기 위한 추가적인 연구가 필요하다. Heater trigger switch의 스위칭 특성을 향상시킬 수 있는 한 가지 방법으로 제안될 수 있는 것이 부분적으로 trigger part에 주 코일과는 다른 특성을 가지는 HTS 선재를 사용하는 것이다. 이를 적용하기 위해서는 필연적으로 서로 다른 특성을 가지는 $\mathrm{HTS}$ 선재 간 접합이 필요하다. 이전까지 접합에 대한 연구는 주로 접합 시 발생하는 접합 저항에 의해 발생하는 줄열에 의한 단점을 보완하기 위해 접합 저항을 낮추는데 초점을 맞춰 왔다[2-6]. 그러나 본 논문에서는 접합 저항 자체를 낮추는 것보다 앞서 제안한 방법을 적용하기 위해 이종 선재 간 접합 저항을

* Corresponding author: ysyoon@sau.ac.kr
확인하고 단일 선재 간 접합 저항과 비교하는 것을 목적으로 한다. 따라서 $344 \mathrm{~s}, \mathrm{BSCCO}, \mathrm{GdBCO} \mathrm{CC}$ 선재에 대한 단일 선재, 이종 선재간 접합을 $\operatorname{In}_{66.3} \mathrm{Bi}_{33.7}$ 와 $\mathrm{Pb}_{63} \mathrm{Sn}_{37} 2$ 가지 solder를 이용하여 진행하였으며 [7], 접합 후 전류-전압 특성과 접합 저항을 측정하였다[3].

\section{2. 본 론}

2.1. 실험 준비

실험에 필요한 시료 제작에 사용된 선재는 Powder in tube (PIT)방법으로 제작된 안정화재가 SUS (3-ply) 재질인 $\mathrm{BSCCO}$ 선재, 안정화재가 Stainless Steel 재질인 $344 \mathrm{~S}$ 선재와 안정화재가 Copper인 $\mathrm{GdBCO} \mathrm{CC}$ 선재, 총 3 가지의 선재를 사용하였다. 사용된 각 선재의 사양은 TABLE I 과 같다.

사용된 Solder는 녹는점이 $72{ }^{\circ} \mathrm{C}$ 인 고체 타입의 $\mathrm{In}_{66.3} \mathrm{Bi}_{33.7}$ 와 $183^{\circ} \mathrm{C}$ 인 Paste 타입의 $\mathrm{Pb}_{63} \mathrm{Sn}_{37} 2$ 가지로 각 Solder의 녹는점이 다르기 때문에 어떤 Solder를 사용하였는가에 따라서 접합 시 적용하는 온도가 Fig. 1. 와 같이 서로 다르게 된다[8]. $\operatorname{In}_{66.3} \mathrm{Bi}_{33.7}$ 의 경우 $100{ }^{\circ} \mathrm{C}$ 에 도달했을 때, $\mathrm{Pb}_{63} \mathrm{Sn}_{37}$ 의 경우 $160{ }^{\circ} \mathrm{C}$ 에 도달했을 때 Fig. 2. 의 Copper RRR100으로 제작된 접합기 내부의 히터의

TABLE I

THE PROPERTIES OF HTS TAPES.

\begin{tabular}{cccc}
\hline Model & $344 \mathrm{~S}$ & BSCCO & GdBCO CC \\
\hline Manufacturer & AMSC & AMSC & SuNAM \\
Width & $4.30 \mathrm{~mm}$ & $4.20 \mathrm{~mm}$ & $4.00 \mathrm{~mm}$ \\
Thickness & $0.15 \mathrm{~mm}$ & $0.27 \mathrm{~mm}$ & $0.09 \mathrm{~mm}$ \\
Length & $14 \mathrm{~cm}$ & $14 \mathrm{~cm}$ & $14 \mathrm{~cm}$ \\
Stabilizer & Stainless Steel & SUS(3-ply) & Copper \\
\hline
\end{tabular}




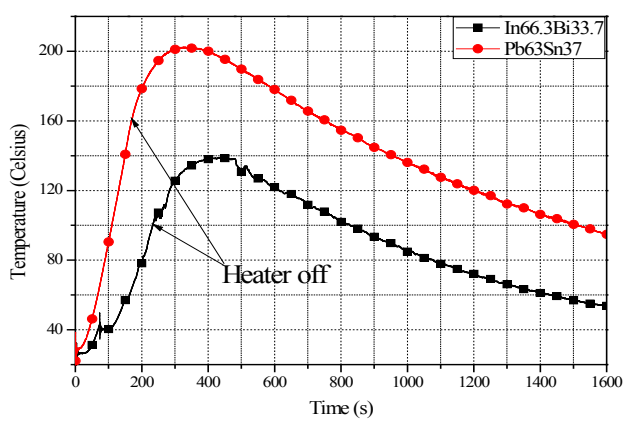

Fig. 1. Temperature profile for each solder.

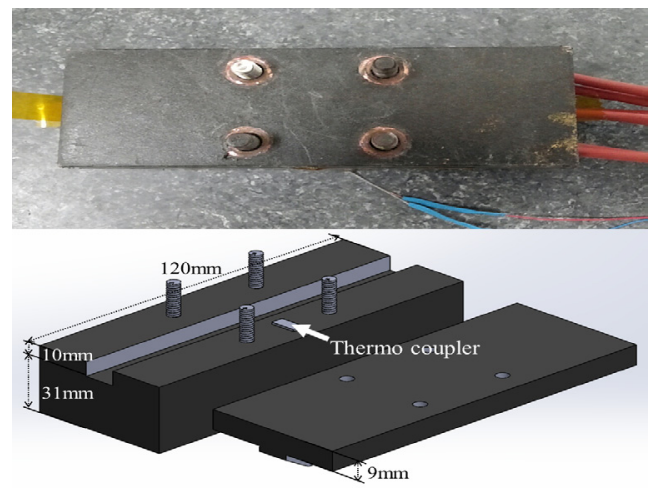

Fig. 2. Temperature and pressure controllable joint machine for HTS tape.

동작을 멈추었고, $\operatorname{In}_{66.3} \mathrm{Bi}_{33.7}$ 의 경우 최대 $139{ }^{\circ} \mathrm{C}$ 까지 온도가 상승하고, $\mathrm{Pb}_{63} \mathrm{Sn}_{37}$ 의 경우 최대 $201{ }^{\circ} \mathrm{C}$ 까지 온도가 상승하게 된다. 해당 온도들은 Fig. 2. 에 표시된 위치, 즉 접합기의 접합하고자 하는 두 선재를 고정시켜 주는 역할을 하는 덮개와 $1.2 \mathrm{~kW}$ 의 전원을 이용하여 열을 공급하는 열선이 포함되어있는 받침 사이에 Thermal coupler를 온도 센서로 이용하여 측정하였다. 또한 두 경우 모두 최고 온도 도달 후 상온까지 자연 냉각을 시켜주었다. $\mathrm{In}_{66.3} \mathrm{Bi}_{33.7}$ 의 경우 녹는점인 $72^{\circ} \mathrm{C}$ 이상의 온도를 1000 초 간 가해주었고, $\mathrm{Pb}_{63} \mathrm{Sn}_{37}$ 의 경우 $183^{\circ} \mathrm{C}$ 이상의 온도를 390초 간 가해주었다.

시료 제작은 $344 \mathrm{~S}$ 와 $\mathrm{GdBCO} \mathrm{CC}$ 선재 간 접합을 하는 경우 Fig. 3. (a)와 같이 초전도 층이 서로 마주보게끔 위치를 시키고, $344 \mathrm{~S}$ 나 $\mathrm{GdBCO} \mathrm{CC}$ 선재와 PIT 공정으로 제조되어 선재의 앞, 뒤 구분이 없는 $\mathrm{BSCCO}$ 선재 간 접합을 하는 경우 Fig. 3. (b) 와 같이 선재를 위치 시키고 Lap joint를 진행하였다. Fig. 1. 의 접합기안에 접합 길이가 $7 \mathrm{~cm}$ 가 되게끔 미리 solder를 바른 선재를 넣고 토크 렌치를 이용하여 4 개의 볼트 각각에 대해 $2.9 \mathrm{~N} \cdot \mathrm{m}$ 의 힘을 가해준 상태로 solder 종류에 따라 Fig. 2. 의 온도 sequence를 적용하여 $344 \mathrm{~S}, \mathrm{BSCCO}, \mathrm{GdBCO} \mathrm{CC}$ 단일 선재 간 접합 시료 6 종류, $344 \mathrm{~S}$ 와 $\mathrm{BSCCO}, 344 \mathrm{~S}$ 와 $\mathrm{GdBCO} \mathrm{CC}, \mathrm{BSCCO}$ 와 $\mathrm{GdBCO} \mathrm{CC}$ 이종 선재 간 접합 시료 6 종류, 총 12 종류의 시료를 제작하였다. 또한 실험의 신뢰성을 위해 동일한 12 종류의 시료를 3 개씩 제작하여 반복 실험을 하였다. $\mathrm{YBCO}$ 선재의 경우 $0.5 \sim 2 \mathrm{~N} \cdot \mathrm{m}$ 의 범위 중 $1 \sim 1.5 \mathrm{~N} \cdot \mathrm{m}$ 의 힘을 가해주었을 때 접합 특성이 가장 좋게 나타난다고 참고 문헌을 통해 나와있으나[4], 실제 실험에 사용된 선재의 경우, 해당 압력에서 적합한 강도를 가지는 접합이 이뤄지지 않아 본 실험에서는 $2.9 \mathrm{~N} \cdot \mathrm{m}$ 의

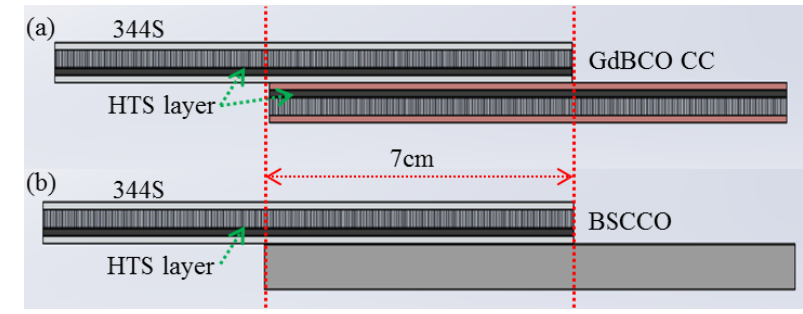

Fig. 3. Jointed method (a) using CC tapes(AMSC 344S, GdBCO CC) for junction (b) using $\mathrm{CC}$ tape and BSCCO tape for junction.

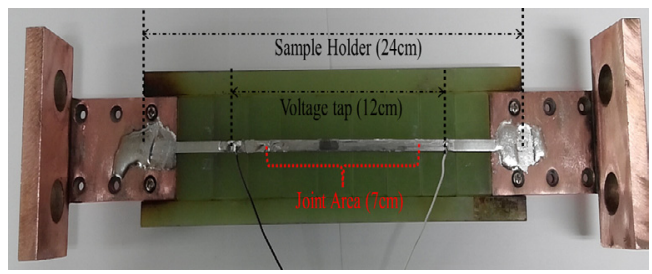

Fig. 4. Jointed sample with sample holder and voltage tap.

힘을 가해주었다. 각 볼트에 적용한 힘을 통해 추정되는 접합 간 압력은 $3.4 \mathrm{~N} / \mathrm{mm}^{2}$ 이다[9]. 또한 온도를 가해줌에 따라 접합기 요소들의 상대적 열팽창에 따른 접합기의 압력변화를 보완하기 위해 $\operatorname{In}_{66.3} \mathrm{Bi}_{33.7}$ 의 경우 $100{ }^{\circ} \mathrm{C}$, $\mathrm{Pb}_{63} \mathrm{Sn}_{37}$ 의 경우 $120^{\circ} \mathrm{C}$ 에서 다시 토크 렌치를 이용하여 초기 가해주었던 것과 동일한 압력을 가해주었다.

\section{2. 실험 결과}

제작된 시료는 Fig. 4. 과 같이 $24 \mathrm{~cm}$ sample holder에 고정한 후 $12 \mathrm{~cm}$ 의 전압 탭을 설치하였다. 전압 탭의 위치는 접합 구간으로부터 $2.5 \mathrm{~cm}$ 씩 떨어진 위치로 이는 전압 탭을 설치하는 동안 가해지는 열에 의해 선재 간 접합에 사용된 solder가 다시 녹는 것을 방지하기 위함이다. 이후 $77 \mathrm{~K}$ 질소 안에 sample holder를 위치 시킨 후, DC power supply를 이용하여 0 A부터 초당 1 A씩 증가시키면서 $100 \mathrm{~A}$ 까지 전류를 흘려주었다. 동시에 시료에 걸리는 전압을 신호처리장치를 이용하여 측정하였다.

본 실험에서 얻은 $\mathrm{I}-\mathrm{V}$ 그래프는 식 (1) 과 같이 표현될 수 있다 $[6,7]$.

$$
V=R_{C} I+V_{C}\left(I / I_{C}\right)^{n}
$$

위 수식에서 $I$ 는 통전전류, $I_{C}$ 는 임계전류로 $1 \mu \mathrm{V} / \mathrm{cm}$ 전압기준을 이용하여 측정된 초전도 선재의 임계전압 값인 $V_{C}$ 에 대비되는 값이다. $n$ 은 물성에 의존하는 값이다. $R_{C}$ 는 접합 저항으로 $\mathrm{I}-\mathrm{V}$ 그래프로부터 임계전류 이하에서 생기는 기울기를 이용하여 계산함으로써 접합 저항을 계산하였다.

\subsection{1. $\operatorname{In}_{66.3} \mathrm{Bi}_{33.7}$ 를 이용한 시료의 접합 저항}

$\mathrm{In}_{66.3} \mathrm{Bi}_{33.7}$ 로 제작된 6 종류의 시료에 대한 $\mathrm{I}-\mathrm{V}$ 그래프는 Fig. 5. 와 같다. I-V 그래프 전압은 $0 \sim 80 \mathrm{~A}$ 의 전류를 가해줬을 때 선형적으로 증가한다. 그 중 $20 \sim 70 \mathrm{~A}$ 구간을 (2)의 임계전류 이하 부분, 즉 $R_{C}=V / I$ 을 적용하여 구한 접합 저항을 계산하였다. 이 접합 저항과 각 시료의 접합 면적을 이용하여 계산한 단위 면적 당 접합 저항, 표준오차를 TABLE II 에서 확인할 수 있다. 


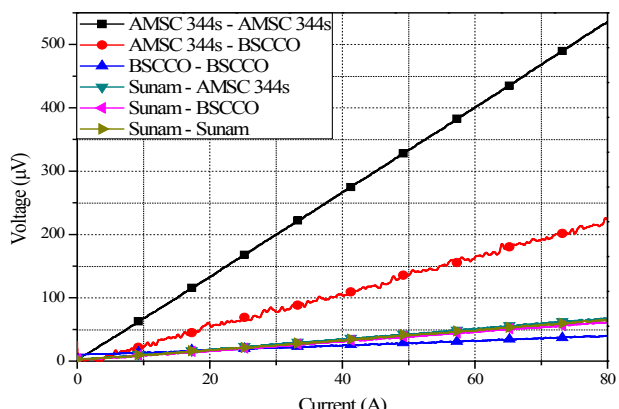

Fig. 5. Current-Voltage characteristics of 6 samples using $\operatorname{In}_{66.3} \mathrm{Bi}_{33.7}$ for joint.

TABLE II

JOINT RESISTANCES OF 6 SAMPLES USING IN ${ }_{66.3} \mathrm{BI}_{33.7}$ FOR JOINT.

\begin{tabular}{ccc}
\hline Sample & $\begin{array}{c}\text { Joint resistance } \\
\text { (Joint resistance per unit area) }\end{array}$ & Standard Error \\
\hline 344S-344S & $\begin{array}{c}6.72 \mu \Omega \\
\left(2.23 \mu \Omega / \mathrm{cm}^{2}\right)\end{array}$ & $0.62 \mathrm{n} \Omega$ \\
& $\begin{array}{c}5.51 \mu \Omega \\
\left(1.87 \mu \Omega / \mathrm{cm}^{2}\right)\end{array}$ & $1.33 \mathrm{n} \Omega$ \\
344S- BSCCO & $\begin{array}{c}0.81 \mu \Omega \\
\text { GdBCO CC-344S }\end{array}$ & $0.30 \mathrm{n} \Omega$ \\
& $\begin{array}{c}\left.0.29 \mu \Omega / \mathrm{cm}^{2}\right) \\
0.80 \mu \Omega\end{array}$ & $0.12 \mathrm{n} \Omega$ \\
GdBCO CC- GdBCO CC & $\left(0.28 \mu \Omega / \mathrm{cm}^{2}\right)$ & \\
GdBCO CC-BSCCO & $0.75 \mu \Omega$ & $0.25 \mathrm{n} \Omega$ \\
BSCCO-BSCCO & $\left(0.27 \mu \Omega / \mathrm{cm}^{2}\right)$ & $0.37 \mu \Omega$ \\
$\left(0.13 \mu \Omega / \mathrm{cm}^{2}\right)$ & $0.25 \mathrm{n} \Omega$ \\
\hline
\end{tabular}

대체적으로 $\mathrm{BSCCO}$ 선재의 안정화재가 $\mathrm{SUS}(3-\mathrm{ply})$ 재질인데 반해 접합에 이용했을 때, 접합 저항이 작게 측정되었다. 또한 안정화재가 Stainless steel인 344s 선재의 경우, 같은 재질인 $\mathrm{BSCCO}$ 선재에 비해 접합에 이용했을 경우 대체적으로 접합 저항이 크게 측정되었다. $\mathrm{GdBCO} \mathrm{CC}$ 선재의 경우, $344 \mathrm{~S}$ 선재에 비해 접합 저항이 작으나 $\mathrm{BSCCO}$ 선재보다는 크게 측정되었다.

\subsection{2. $\mathrm{Pb}_{63} \mathrm{Sn}_{37}$ 을 이용한 시료의 접합 저항}

접합 저항과 단위 면적당 접합 저항의 크기는 TABLE III과 같다. $\operatorname{In}_{66.3} \mathrm{Bi}_{33.7}$ 를 이용하여 제작한 경우와 마찬가지로 접합 저항의 크기는 $344 \mathrm{~s}$ 선재와 $\mathrm{BSCCO}$ 선재를 이용한 시료가 가장 크고, $344 \mathrm{~s}$ 단일 선재를 이용한 선재, $\mathrm{GdBCO} \mathrm{CC}$ 선재와 $344 \mathrm{~s}, \mathrm{GdBCO} \mathrm{CC}$ 단일 선재, $\mathrm{GdBCO} \mathrm{CC}$ 선재와 $\mathrm{BSCCO}$ 선재, $\mathrm{BSCCO}$ 단일 선재를 이용한 순으로 작아진다. 결국 안정화재가 Stainless steel 인 344s를 이용했을 때가 접합 저항이 가장 크게 나타나고, 안정화재는 동일하게 SUS (3-ply)이지만 $\mathrm{BSCCO}$ 선재를 사용했을 때가 $\mathrm{GdBCO} \mathrm{CC}$ 선재를 사용했을 때보다 접합 저항이 작게 측정되었다.

\section{3. 실험 분석}

접합 저항의 크기는 접합에 사용된 두 선재의 안정화재가 Stainless steel나 SUS (3-ply)인 경우, 3종류의 시료 중 $344 \mathrm{~S}$ 단일 선재 간 접합 시료의 값이 가장 크다. 동일한 양의 전류가 흘렀을 때 열량 발생률이 높은 stainless steel이 안정화재로 사용되었기 때문에 그 값이 큰 것으로 예상되나 측정 결과 중 $\mathrm{BSCCO}$ 선재의 경우 접합 저항의 크기가 가장 작게 측정되었다. 또한 사용된 solder의 종류에 따라 접합 저항의 크기 자체는 변하였지만, 제작된

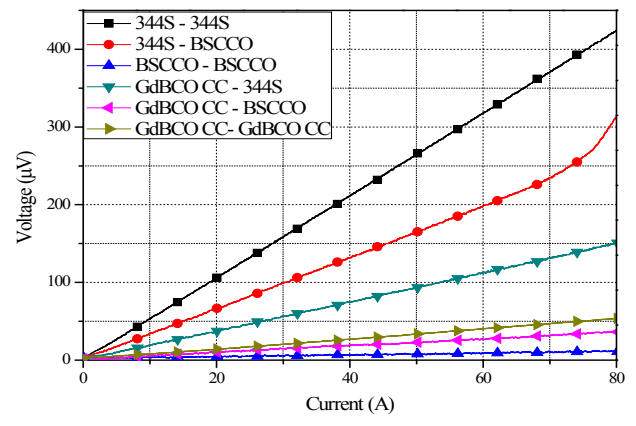

Fig. 6. Current-Voltage characteristics of 6 samples using $\mathrm{Pb}_{63} \mathrm{Sn}_{37}$ for joint.

TABLE III

JOINT RESISTANCES OF 6 SAMPLES USING $\mathrm{PB}_{63} \mathrm{SN}_{37}$ FOR JOINT.

\begin{tabular}{ccc}
\hline Sample & $\begin{array}{c}\text { Joint resistance } \\
\text { (Joint resistance per unit area) }\end{array}$ & $\begin{array}{c}\text { Standard } \\
\text { Error }\end{array}$ \\
\hline 344S-344S & $5.31 \mu \Omega$ & $0.32 \mathrm{n} \Omega$ \\
344S- BSCCO & $\left(1.76 \mu \Omega / \mathrm{cm}^{2}\right)$ & \\
& $3.31 \mu \Omega$ & \\
GdBCO CC-344S & $\left(1.13 \mu \Omega / \mathrm{cm}^{2}\right)$ & $0.55 \mathrm{n} \Omega$ \\
& $1.90 \mu \Omega$ & \\
GdBCO CC- GdBCO CC & $\left(0.68 \mu \Omega / \mathrm{cm}^{2}\right)$ & $0.27 \mathrm{n} \Omega$ \\
& $0.67 \mu \Omega$ & \\
GdBCO CC-BSCCO & $\left(0.23 \mu \Omega / \mathrm{cm}^{2}\right)$ & $0.33 \mathrm{n} \Omega$ \\
BSCCO-BSCCO & $0.44 \mu \Omega$ & \\
& $\left(0.16 \mu \Omega / \mathrm{cm}^{2}\right)$ & $0.20 \mathrm{n} \Omega$ \\
$0.12 \mu \Omega$ & \\
\hline
\end{tabular}

시료들의 크기 순서는 동일한 것으로 보아, solder의 종류만 결정된다면 이종선재 간 접합에 있어 접합에 사용하는 선재의 종류가 접합 저항의 크기에 큰 영향을 끼친다는 것을 확인할 수 있다. 또한 단일, 이종 선재 간 접합 저항을 살펴본 결과, 단일 선재 간 접합 저항이 큰 선재를 이종 선재 간 접합에 사용한 경우 역시 그 값이 크고 단일 선재 간 접합 저항이 작은 경우 역시 동일 하다는 것을 확인할 수 있다. 이를 통해 이종 선재 간 접합 저항의 크기는 접합에 사용되는 각 선재의 단일 접합 저항을 통해 어느 범위에 있을지 예측 가능할 것이란 것을 확인할 수 있다.

\section{3. 결 론}

본 연구에서는 Superconducting power supply, SMES 등의 heater trigger switch의 온도 제어 과정에서 발생하는 시간 지연을 줄이기 위해 부분적으로 trigger part에만 주 코일에 비해 상대적으로 줄열이 크게 발생할 수 있는 다른 종류의 선재를 접합하여 사용하기 위해 이종 선재 간 접합과 단일 선재 간 접합 실험을 통해 전류-전압 특성과 접합 저항을 확인하였다. 접합 저항을 측정한 결과 안정화재가 stainless steel 인 $344 \mathrm{~s}$ 선재만을 이용한 시료의 접합 저항이 가장 크고, $344 \mathrm{~s}$ 와 안정화재가 $\mathrm{SUS}(3-\mathrm{ply})$ 인 $\mathrm{BSCCO}$ 를 접합한 시료, 안정화재가 Copper인 $\mathrm{GdBCO} \mathrm{CC}$ 선재와 $344 \mathrm{~s}$ 선재를 접합한 시료, $\mathrm{GdBCO} \mathrm{CC}$ 선재만을 이용한 시료, $\mathrm{GdBCO} \mathrm{CC}$ 선재와 $\mathrm{BSCCO}$ 선재를 이용한 시료, $\mathrm{BSCCO}$ 단일 선재를 이용한 시료 순으로 접합 저항이 작아진다. 또한 $\operatorname{In}_{66.3} \mathrm{Bi}_{33.7}$ 와 $\mathrm{Pb}_{63} \mathrm{Sn}_{37}$ 2가지 solder 중 $\mathrm{Pb}_{63} \mathrm{Sn}_{37}$ 을 사용한 경우가 $\mathrm{GdBCO} \mathrm{CC}$ 선재와 $344 \mathrm{~s}$ 선재를 접합 한 경우를 제외하고 
접합 저항이 더 작게 측정되었다. 초기 목적에 부합하기 위해서 안정화재가 stainless steel인 선재와 Copper인 선재 간 접합 저항과 Copper 단일 선재 간 접합 저항을 비교한 결과 단일 선재 간 접합 저항이 큰 $344 \mathrm{~S}$ 선재는 이종 선재 간 접합 저항 역시 크고, 반대의 경우인 $\mathrm{BSCCO}$ 선재는 이종 선재 간 접합 저항 역시 작다. 이를 통해 이종 선재 간 접합을 할 시, 접합에 사용되는 선재 각각에 대한 단일 선재 간 접합 저항을 안다면 이종 선재 간 접합 저항이 어느 범위에 있을지 예상이 가능하다는 것을 알 수 있다.

본 연구 결과는 다양한 선재의 조합을 통해 Heater trigger switch가 포함된 에너지 저장 장치 등의 설계에 있어 유용한 파라미터로 활용될 수 있을 것으로 기대된다.

\section{ACKNOWLEDGMENT}

This work was supported by Basic Science Research Program through the National Research Foundation of Korea funded by the Ministry of Education under Contract 2011-0009232.

\section{REFERENCES}

[1] Hyun Chul Jo, Seong Eun Yang, Young Jae Kim, Ki Sung Chang, Jae Young Jang, Yong Soo Yoon, Yoon Do Chung, Ho Min Kim, and Tae Kuk Ko, "Experimental Analysis of Flux Pump for Compensating Current Decay in the Persistent Current Mode Using HTS Magnet," IEEE Transactions on Applied Superconductivity, vol. 20, no. 3, pp. 1693-1696, 2010.

[2] Jun Lu, Ke Han, William R. Sheppard, Youri L. Viouchkov, Kenneth W. Pickard, and William Denis Markiewicz, "Lap Joint Resistance of YBCO Coated Conductors," IEEE Transactions on Applied Superconductivity, vol. 21, no. 3, pp. 3009-3012, 2011.
[3] S. H. Park, H.-S. Chang, Y. S Kim, S. Y. Shim, S. J. Oh, H. C. Kim, S. H. Bang, and H.-C. Ri, "I-V characteristics and contact resistance of jointed BSCCO tape," Proceeding of the Korea Institute of Applied Superconductivity and Cryogenics Conference, pp.163-164, Feb. 2002.

[4] Hyung Jun Kim, Hyun Chul Jo, Ki Sung Chang, Min Kyu Yang, Min Cheol Ahn, and Tae Kuk Ko, "A Study on a Splice Method of YBCO Coated Conductors with Curvature for HTS Magnet Application," Progress in Superconductivity and Cryogenics, vol. 12, no. 1, pp. 17-21, Mar. 2010.

[5] G. J. Homer, P. J. Houzego, C. A. Scott, and M.N. Wilson, "A Thermally Switched Flux pump, "IEEE Transactions on Magnetics, vol. MAG-11, no. 2, pp. 576-579, Mar. 1975.

[6] Dong Keun Park, Min Cheol Ahn, Ho Min Kim, H. G. Lee, Ki Sung Chang, Sand Jin Lee, Seong Eun Yang, and Tae Kuk Ko, "Analysis of a Joint Method Between Superconducting YBCO Coated Conductors," IEEE Transactions on Applied Superconductivity, vol. 17, no. 2, pp. 3266-3269, Jun. 2007.

[7] Carlos A. Baldan, Ulisses R. Oliveira, Carlos Y. Shigue, and Ernesto Ruppert Filho, "Evaluation of Electrical Properties of Lap Joints for BSCCO and YBCO Tapes," IEEE Transactions on Applied Superconductivity, vol. 19, no. 3, pp. 2831-2834, Jun. 2009.

[8] T. A. Nguty, S. Budiman, D. Rajkumar, R. Solomon and N. N. Ekere, "Understanding the Process Window for Printing Lead-Free Solder Pastes," Electronic Components \& amp; Technology Conference, 50th, NO. 2, pp. 1426-1435, May 2000.

[9] G. Celentano, A. Augieri, A. Mauretti, A. Vannozzi, A. Angrisani Armenio, V. Galluzzi, S. Gaudio, A. Mancini, A. Rufoloni, I. Davoli, C. Del Gaudio, and F. Nanni, "Electrical and Mechanical Characterization of Coated Conductors Lap Joints," IEEE Transactions on Applied Superconductivity, vol. 20, no. 3, pp. 1549-1552, Jun. 2010. 